\title{
Crystal surface integrity and diffusion measurements on Earth and planetary materials
}

\author{
E.B. Watson*1 ${ }^{1}$ D.J. Cherniak ${ }^{1}$, J.B. Thomas ${ }^{2}$, J.M. Hanchar ${ }^{3}$, R. Wirth ${ }^{4}$ \\ ${ }^{1}$ Department of Earth and Environmental Sciences, Rensselaer Polytechnic Institute, Troy, New York \\ 12180, U.S.A. \\ ${ }^{2}$ Department of Earth Sciences, Syracuse University, Syracuse, New York 13224, U.S.A. \\ ${ }^{3}$ Department of Earth Sciences, Memorial University of Newfoundland, St. John's A1B 3X5, Canada \\ ${ }^{4}$ Helmholtz Centre Potsdam, German Research Centre GFZ, Telegrafenberg, 14476 Potsdam, Germany
}

*corresponding author (watsoe@ @rpi.edu)

\begin{abstract}
Characterization of diffusion behavior in minerals is key to providing quantitative constraints on the ages and thermal histories of Earth and planetary materials. Laboratory experiments are a vital source of the needed diffusion measurements, but these can pose challenges because the length scales of diffusion achievable in a laboratory time are commonly less than 1 micrometer. An effective strategy for dealing with this challenge is to conduct experiments involving inward diffusion of the element of interest from a surface source, followed by quantification of the resulting diffusive-uptake profile using a high-resolution depth-profiling technique such as Rutherford backscattering spectroscopy (RBS), nuclear reaction analysis (NRA), or ion microprobe (SIMS). The value of data from such experiments is crucially dependent on the assumption that diffusion in the near-surface of the sample is representative of diffusion in the bulk material. Historical arguments suggest that the very process of preparing a polished surface for diffusion studies introduces defects - in the form of dislocations and cracks - in the outermost micrometer of the sample that make this region fundamentally different from the bulk crystal in terms of its diffusion properties. Extensive indirect evidence suggests that, in fact, the near-surface region of carefully prepared samples is no different from the bulk crystal in terms of its diffusion properties. A direct confirmation of this conclusion is nevertheless clearly important. Here we use transmission electron microscopy to confirm that the near-surface regions of olivine, quartz and feldspar crystals prepared using careful polishing protocols contain no features that could plausibly affect diffusion. This finding does not preclude damage to the mineral structure from other techniques used in diffusion studies (e.g., ion implantation), but even in this case the role of possible structural damage can be objectively assessed and controlled. While all evidence points to the reliability of diffusivities obtained from in-diffusion experiments, we do not recommend experiments of this type using a powder source as a means of obtaining diffusant solubility or partitioning information for the mineral of interest.
\end{abstract}

keywords: diffusion measurements; crystal surfaces; depth profiling; Rutherford backscattering; nuclear reaction analysis; ion microprobe 


\section{Introduction}

1

Knowledge of diffusion rates of atoms in Earth and planetary materials can yield information on sample histories that is obtainable by no other means. Constraints on the temperature dependence of diffusion, in particular, are key to the quantitative reconstruction of thermal histories (cooling and/or heating paths) and to assessment of the reliability of age information acquired by measurement of accumulated radiogenic or cosmogenic isotopes. Given the importance of diffusion in geo-/ cosmochemistry and petrology, it is not surprising that the data base of diffusion measurements on minerals has expanded dramatically in recent decades (see summary in Zhang and Cherniak, 2010). Many of the new data have come from laboratory experiments designed to introduce a diffusant of interest into a sample and measure its migration progress at high temperature over a period of days to months. However, practical constraints on experiment duration lead to significant challenges in the analysis of diffusion experiments. In particular, because the diffusivities of many elements in crystals of geological interest are quite low, the length scales of transport in a laboratory time frame are commensurately small -in many cases considerably less than a micrometer.

In most laboratory protocols, diffusion experiments are set up in such a way that the diffusant of interest is supplied by a source at or near the mineral surface. This source could be in the form of a contacting powder (e.g., Cherniak and Watson, 1994; Van Orman et al., 2002; see also Watson and Dohmen, 2010 and references therein), a thin film deposited by pulsed laser deposition (PLD; see Chrisey and Hubler, 1994; Lowndes et al., 1996; Dohmen et al., 2002a; 2007; Marquardt et al., 2010), a contacting aqueous solution (Fortier and Giletti, 1991; Giletti, 1991), a precipitate formed by evaporation of an aqueous solution (e.g., Sneeringer et al., 1984; Chakraborty and Rubie, 1996; Van Orman et al., 1998; 2001), a gaseous atmosphere (e.g., Sharp et al., 1991; Wartho etal., 1999; Thomas et al,. 2008) or a near-surface concentration horizon deposited by ion implantation (e.g., Cherniak et al., 1991; Cherniak and Ryerson, 1993; Cherniak et al., 2014). The combination of a surface source and a 
24 sub-micron diffusion length scale raises a vitally important question about the samples used for

25 laboratory experiments: Is the near-surface region representative of the "deep" crystal structure in terms of its volume diffusion properties? If the results of a diffusion experiment are to be taken as

27 representative of the bulk crystal and accorded broad geochemical value, the answer to this question must be yes. If the near-surface of the mineral differs from the bulk structure in some way that affects diffusion, the value of the measurement may be compromised. The purpose of the study described here is to evaluate directly the assumption that the near-surface of appropriately prepared samples is representative of the bulk structure.

\section{Definition of "near-surface"}

The adjective "near-surface" is a relative descriptor, so clarification of terms is needed in order for the following discussion to be meaningful. It has been recognized for decades that the immediate nearsurface (INS) of crystals is structurally and chemically distinct from the deep (bulk) crystal structure even under conditions of chemical and mechanical equilibrium (e.g., Hall, 1953; Kingery, 1984; and reviews by Dowben and Miller, 1990 and Sutton and Balluffi, 1995). Adjustments of bond lengths and bond angles in this region occur as near-surface atoms relax from their regular lattice positions due to the proximity of a free surface or other phase discontinuity. Differences in the local bonding environment between the INS and the bulk crystal lead, in turn, to differences in equilibrium impurity content, commonly referred to as surface- or interface segregation in the materials science literature. Importantly, the length scale of this particular type of near-surface structural and chemical anomaly is now understood to be only 1-2 nm, as determined by direct measurements using X-ray reflectivity (e.g., Fenter et al., 2000a,b; Schlegel et al., 2002; Fenter et al., 2003; Zhang et al,. 2007) and also from molecular dynamics simulations (e.g., Lanzillo et al., 2014). Not surprisingly, the INS is similar in width to grain boundaries (e.g., Hiraga and Kohlstedt, 2007). Because of the distorted atomic structure in the INS relative to the bulk structure, diffusion of atoms within this 1- to $2 \mathrm{~nm}$-wide region may indeed differ from diffusion at 
depth in the lattice (e.g., Lanzillo et al., 2014); however, no research group of which we are aware is

49 publishing volume diffusion data based upon profiles only 1-2 $\mathrm{nm}$ in length. As far as volume diffusion measurements in crystals are concerned, the structurally-relaxed immediate near-surface (i.e.,

51 outermost 2-3 polyhedral layers) of a crystal is of no relevance to the present discussion [Note,

52 however, that this region may influence the trace-element or isotopic composition of a crystal that is

53 acquired during growth (Watson, 2004; Lanzillo et al., 2014; Watkins et al., 2016)].

Beyond the INS, the term "near-surface" has also been applied to the region of a crystal subject to structural damage, mainly in the form of cracks and dislocations, as a consequence of the cutting,

56 grinding and polishing steps used to produce the surface intended for diffusion experiments. The

57 introduction of damage to the atomic structure of crystals through aggressive grinding and polishing was

58 recognized nearly 100 years ago (Beilby, 1921). The phenomenon seems to be best documented in

59 metals (see, e.g., French, 1933; Finch et al., 1934), but is widely recognized in oxides and silicates as something to be avoided in samples intended for electron backscatter diffraction (EBSD) measurements,

61 in which the signal comes from the outermost $\sim 2 \mathrm{~nm}$ of the crystal (Winkelmann, 2020; Zaefferer, 2007).

62 Reddy and Cooper (1982) also noted an effect of surface-preparation damage on oxygen diffusion in

63 sapphire, and Pinilla et al. (2012) recently presented a TEM image of obvious near-surface damage in a

64 gem-quality olivine crystal subjected to an unspecified grinding and polishing procedure. Because this

65 kind of damage is characterized by extended defects - and because the damaged region can reach

66 hundreds of nanometers into the crystal (see Figure 1 of Pinilla et al., 2012) —it certainly has the

67 potential to influence the results of experiments in which near-surface diffusion profiles are generated

68 and measured. Like other laboratory groups involved in the study of slow-diffusing elements using

69 depth-profiling techniques (e.g., Farver and Giletti, 1985; Jaoul et al., 1983; Ryerson et al., 1989; Giletti,

70 1991; Ryerson and McKeegan 1994; Chakraborty and Rubie, 1996; Van Orman et al., 1998; 2001; 2002;

71 Tirone et al., 2005; Dohmen et al., 2002b, 2007; Sano et al., 2011; Marschall et al., 2013), the RPI 
72 research group typically designs experiments to produce diffusion profiles in the $\sim 50$ - to 500 -nm depth

73 region, simply because longer profiles are usually precluded by practical constraints on experiment

74 duration. Our preferred analytical techniques — Rutherford backscattering spectroscopy (RBS) and

75 nuclear reaction analysis (NRA) — are well suited to this depth range. Depth-profiling by ion microprobe

76 (SIMS) works best in the depth range between $100 \mathrm{~nm}$ and 1-2 $\mu \mathrm{m}$ (see, e.g., Van Orman et al., 2001).

In the present study, we use transmission electron microscopy (TEM) to demonstrate that proper

79 in terms of atomic structure and presence of extended defects. Consequently, a diffusion profile acquired from this region by depth-profiling with RBS, NRA or SIMS should accurately reflect volume

81 diffusion in the bulk crystal. There exist precedents to the present study in which TEM images of the

82 near-surface of a diffusion sample are provided (e.g., Ratteron et al., 1998; Marquardt et al., 2010;

83 Pinilla et al., 2012) but these generally focus upon a single mineral, and evaluation of the near-surface

84 for possible polishing damage is not the primary thrust of the work.

\section{Materials, preparation and imaging}

\subsection{Cutting and polishing}

The materials examined by TEM in this study were San Carlos Fogo olivine (SCO), commercial synthetic (hydrothermal) quartz, and Itrongay orthoclase from Madagascar. These minerals were

89 chosen because they represent a range of silicate structures (nesosilicate to tectosilicate) with and without cleavage, and they are all common targets for diffusion studies by ourselves and other research

91 groups. Tabular pieces of SCO and quartz $\sim 1 \mathrm{~mm}$ thick and $\sim 4 \mathrm{~mm}$ on a side were cut from $\mathrm{cm}$-sized

92 specimens with a low-speed diamond saw (SCO cut $\perp c$; quartz //c). Two orthoclase slabs of similar

93 thickness were prepared by manually cleaving the Itrongay material along (010) with a knife; one of

94 these slabs was set aside for TEM work directly on the cleaved surface. The other orthoclase slab and 
the SCO and quartz slabs were polished on one side following the procedure used at RPI to prepare all of

96 our samples for diffusion studies (see Watson and Cherniak, 2003; Thomas et al., 2008; Cherniak et al.,

97 2014). Briefly, the slabs are attached to a 2.5-cm diameter brass or aluminum disk with Crystal Bond ${ }^{\circledR}$ and ground manually, with successively finer SiC metallographic paper, starting at $240(53 \mu \mathrm{m})$ grit and progressing down through 320 - and $400-$ to $600(16 \mu \mathrm{m})$ grit. We do not use a lapidary wheel, and the force applied to the metal disk is limited to what a person can sustain with two fingers for a protracted period of time. The time required for these grinding steps depends upon human factors and also upon the freshness of the SiC paper. Key to the success of the process is assuring that the scratches produced by a particular SiC grit are removed by the subsequent grit. Perhaps contrary to expectation, the magnitude of the scratches remaining on the sample surface after grinding with a particular abrasive bears no resemblance to the size of abrasive particles; for example, $16-\mu \mathrm{m}$ grit does not leave $16-\mu \mathrm{m}$ deep furrows in the sample surface $(1 \mu \mathrm{m}$ is a better estimate of the scratch depth at this stage; see 107 Figure $1 b)$.

The final polishing steps are performed with a Minimet ${ }^{\circledR}$ automated polisher manufactured by Buehler, Ltd. This device features a steel "finger" that engages with a shallow well in the back of the 2.5$\mathrm{cm}$ metal disk to which the sample is adhered. The finger exerts downward force on the metal disk and

111 moves it in an eccentric circular pattern over a 7-cm (dia.) glass platen covered with self-adhering

112 Buehler Texmet ${ }^{\circledR}$ polishing cloth. The first automated polishing step is done using an aqueous

113 suspension of $1-\mu \mathrm{m}$ alumina at a rotation speed of $200-300 \mathrm{rpm}$ and a sample load of 2-3 $\mathrm{N}$ for a

114 duration of 1-2 hours. Following this step, the sample surface is inspected optically in reflected light to 115 ensure that scratches from the earlier SiC polishing steps have been removed; it is then returned to the 116 automated polisher and subjected to an additional 2-4 hours of polishing with 40- or 60-nm colloidal 117 silica suspension. For this last polishing step, a higher sample load ( 4-5 N) and slower rotation rate 118 (100-150 rpm) are used to achieve the final chemo-mechanical polish. The total amount of material 
removed during the two automated polishing steps is typically $75-100 \mu \mathrm{m}$, with the final colloidal silica stage accounting for $10-20 \mu \mathrm{m}$ (the removal rate during the colloidal silica treatment is $2-8 \mu \mathrm{m} / \mathrm{h}$, depending on the identity and surface area of the sample and the details of the polisher settings).

\subsection{SEM documentation of polishing progress}

In a recent publication (Cherniak et al., 2014), we reported on the "external" character of pure Mg-olivine surfaces prepared as described above, which were imaged using atomic force microscopy (AFM) and field-emission electron microscopy (FE-SEM). A key conclusion from that study is that the final polished surface is flat at nearly the atomic scale, with a typical relief of $\pm 0.2 \mathrm{~nm}$ relative to the mean surface position over a distance of several micrometers. The AFM and FE SEM images presented by Cherniak et al. (2014) were limited in showing only the final polished surface of an Mg-olivine crystal, without detailing progress through the sequence of steps. Here we illustrate 4 stages of preparation of the same synthetic Mg-olivine used in our 2014 study (from Morion, Inc.) with a sequence of FE-SEM images (Figure 1). Unlike the TEM images described below (sections 3.2 and 4), these FE-SEM images cannot resolve structural defects at the atomic scale, but they do confirm the initial presence, and subsequent elimination, of near-surface structural damage in the form of scratches and cracks at the sub-micron scale. The poor quality of the olivine near-surface after initial cutting and grinding with 240grit SiC paper is obvious in Figure 1a, but after the final colloidal silica step (Figure 1d) the near-surface appears featureless even at $\sim 10 \mathrm{~nm}$ resolution. In fact — within the resolving power of the FE-SEM- the near-surface appears to be of excellent quality even before polishing with colloidal silica (that is, after the 1- $\mu \mathrm{m}$ alumina step; Figure 1c).

As effective as FE-SEM images are in portraying polishing progress and surface topography, they cannot resolve dislocations and other extended defects, which-if present-might contribute to anomalous diffusion behavior. Vetting of the near-surface at this magnification requires TEM imaging. 

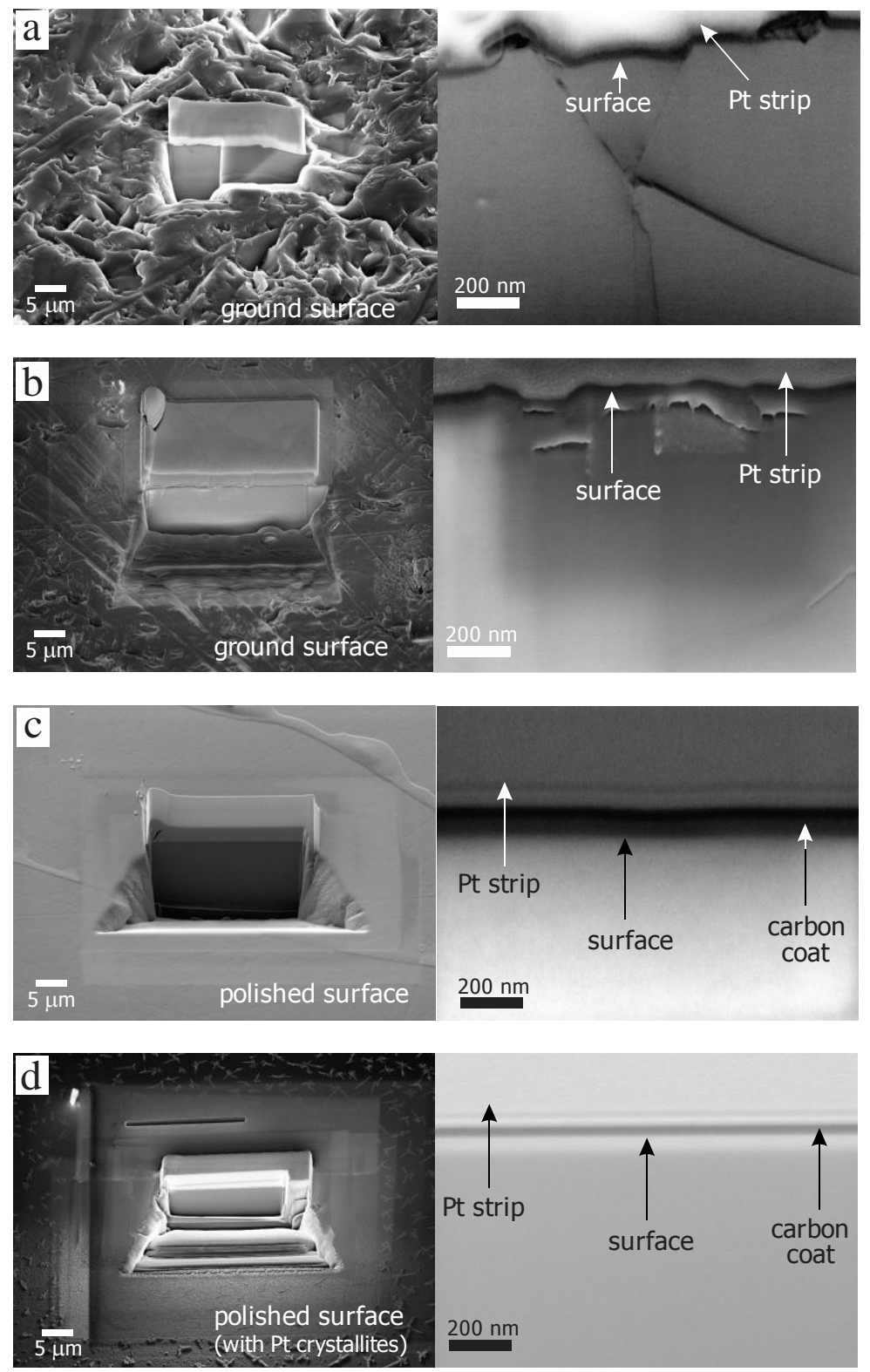

Figure 1. Field-emission secondary-electron images showing four stages of preparation of a forsterite sample surface. Frames (a) - (d) show the state of the surface at two magnifications after polishing with 53-mm SiC, 16-mm SiC, 1- $\mu$ m alumina, and 60-nm colloidal $\mathrm{SiO}_{2}$, respectively. At the center of each left-hand panel is a rectangular pit cut normal to the polished surface with a FIB. The corresponding right-hand panels shows the vertical face of the pit at high magnification, with a Pt strip at the top that was deposited to protect the surface during milling. Note the pitted and fractured nature of the surface at the left in (a); note also that these features are markedly reduced in (b) and completely absent in (c) and (d). The surface of the sample in (d) is speckled with small Pt crystallites that condensed from vapor during deposition of the Pt protective strip on the crystal surface inside the SEM chamber prior to FIB milling; these are unrelated to the forsterite and clearly absent in the high-magnification image at the right, where the surface was protected by the Pt strip. Instrument details: Carl Zeiss 1540 XB FESEM equipped with a FIB column (Canion 31 with liquid Ga source) and gas injection. Highresolution images were collected at $2.5 \mathrm{kV}$ accelerating voltage and $500 \mathrm{pA}$ beam current, which result in a practical resolution of $\sim 5 \mathrm{~nm}$. 


\subsection{Preparation and imaging of TEM foils}

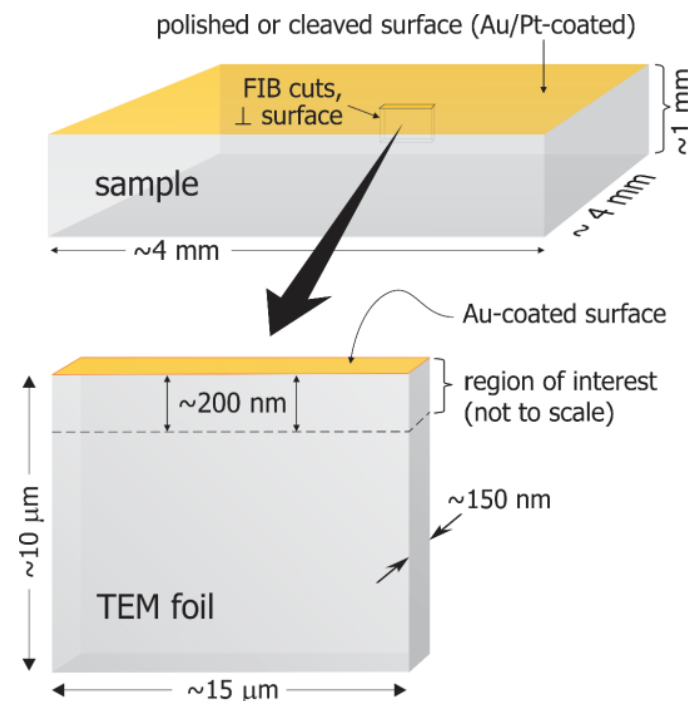

Figure 2. Schematic diagram illustrating FIB cuts made perpendicular to the polished, Au-coated sample surface to obtain TEM foils. Dimensions are approximate, and the width of the region of interest in the TEM foil is not to scale. See text for discussion.

\section{Results}

Figures 3-5 are bright-field TEM images of the near-surface region of SCO, quartz and orthoclase.

156 It is important to note that these are not high-resolution TEM images because the focusing of the 
electron beam required for bright-field image acquisition at high resolution leads to rapid electron-

irradiation damage in silicates, even in a refractory phase like olivine. The rapid accumulation of damage during high-resolution imaging makes it difficult to distinguish between preexisting structural distortion and electron irradiation damage. Given that our goal was to detect structural damage resulting from the polishing process, we specifically avoided high-resolution imaging.

The SCO near-surface is shown at two magnifications in Figure 3 , in which the maximum distance from the surface $(\sim 2 \mu \mathrm{m})$ appears in the upper left corner of Figure 3a. The images are essentially featureless except for minor strain contrast due to local elastic deformation occurring within $\sim 25 \mathrm{~nm}$ of the sample surface, probably resulting from interfacial forces where the gold coating contacts the thin edge of the sample. There are no dislocations visible at depth in the sample and none present as a consequence of sample preparation.
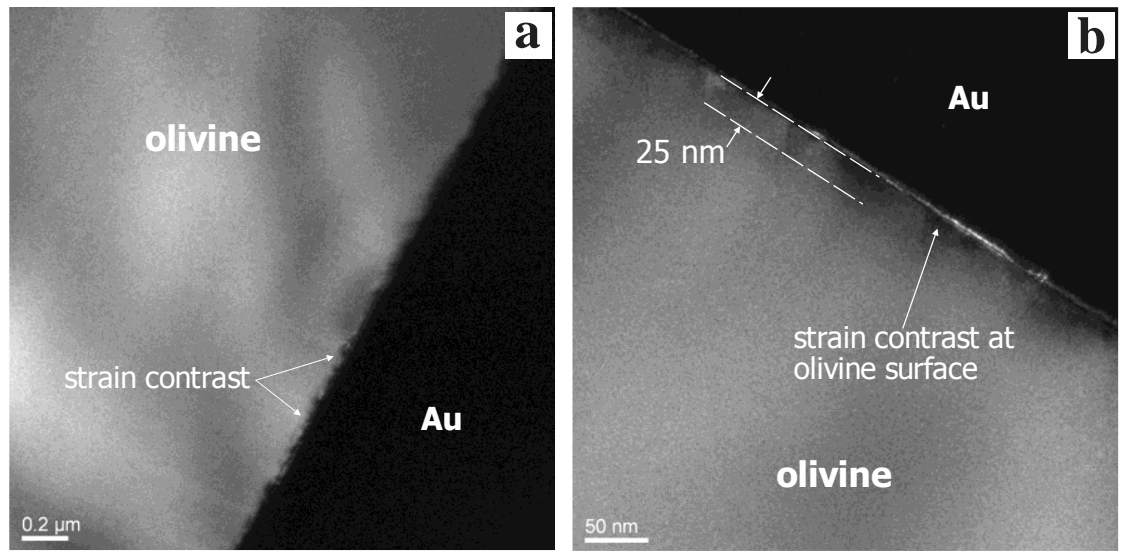

Figure 3. Bright-field TEM images of the near-surface of an SCO crystal that was polished as described in the text. Note that in (a) there is no perceptible difference between the structure $\sim 2 \mu \mathrm{m}$ deep in the crystal (upper left corner) and close to the surface. There is minor roughness evident on the surface of the olivine at the nanometer scale, similar to that documented by Cherniak et al. (2014) by AFM. Roughness at this scale would have a negligible effect on diffusion profiles obtained by RBS or NRA that are at least tens of nanometers long [see discussion in Watson and Dohmen (2010)]. The higher magnification image in (b) reveals a flat gold-olivine interface and minor strain contrast in the outermost $\sim 25 \mathrm{~nm}$ of the crystal. No fractures or extended defects are visible in either image that could conceivably affect diffusion. The strain localized near the surface is probably caused by surface forces between the gold coating and the thin edge of the olivine at the interface between those dissimilar materials. That mismatch causes a slight elastic distortion of the olivine lattice in the outer $\sim 25 \mathrm{~nm}$ (which is only a few unit cells of olivine). Without the gold coating this strain contrast would most likely be absent or undetectable. 
Figure 4 shows similar bright-field TEM images of the near-surface of the Itrongay orthoclase, for

both the polished and cleaved surfaces (Figures $4 a$ and $b$, respectively). As in the olivine case, the near-

172 phenomenon is much more apparent near the cleaved surface.
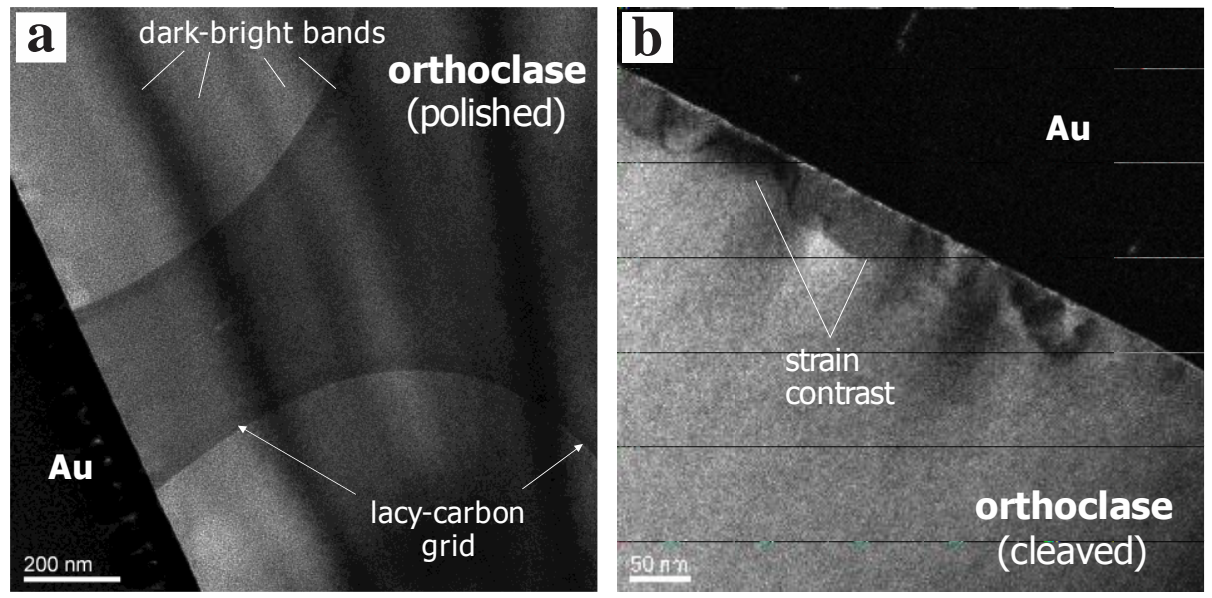

Figure 4. Bright-field TEM images of the near-surface of two different specimens of Itrongay orthoclase. The surface in (a) was polished using the procedure described in the text; that in (b) was prepared by cleaving a crystal, with no subsequent treatment. The lacy-carbon copper grid is visible beneath the foil in (a). The feldspar itself shows a very flat surface against the gold and no difference between the bulk crystal $\sim 1 \mu \mathrm{m}$ from the surface and the outermost $200 \mathrm{~nm}$. The small, rounded, slightly bright regions near the gold/orthoclase interface are believed in this case to be the result of Ga ion implantation. Unevenness in the deposited Au layer may have allowed some of the Ga ions to penetrate the surface of the orthoclase, causing minor structural strain and weak strain contrast seen in the image. The alternating dark and bright bands oriented roughly NW-SE in the image are diffraction contrasts related to the crystal orientation of the orthoclase crystal in the FIB TEM foil. The surface of the cleaved sample in (b) is similarly flat, but in this case strain contrast is clearly visible as a distinct band in the outermost $\sim 50 \mathrm{~nm}$. The presence of the strained region in the cleaved sample is believed to be the result of residual structural distortion (elastic deformation) associated with the cleavage event. This structural distortion could conceivably influence diffusion in the outermost $40-50 \mathrm{~nm}$ of cleaved samples, but it should be borne in mind that: 1) heating to induce diffusion probably causes the strain to relax very quickly; and 2) cleaved surfaces are seldom used in diffusion studies.

Figure 5 is a similar bright-field TEM image of the synthetic quartz crystal near-surface, which

174 reveals no dislocations or extended defects. Several minor bumps are discernible that stand a few $\mathrm{nm}$ above the surface; however, because of their isolated character and small amplitude relative to typical 
177 the other two minerals, quartz shows strain contrast near the sample edge, in this case to depths of up to $\sim 50 \mathrm{~nm}$.

Figure 5. Bright-field TEM image of the near-surface of a polished crystal of synthetic quartz. Features of note include minor strain contrast (due to slight bending of the quartz lattice planes) locally within $\sim 50 \mathrm{~nm}$ of the surface, as well as occasional bumps on the surface of a few nm relief. As described with reference to olivine in Figure 3, this strain contrast is most likely caused by surface forces between the gold coating and the $\mathrm{SiO}_{2}$ at the interface between thin edges of those two dissimilar materials. It is not a given that similar strain would at the interface between a more robust diffusion specimen and diffusant source, $\mathrm{t}$ in a diffusion sample (as opposed to a TEM foil), minor strain arising from the juxtaposition of dis-

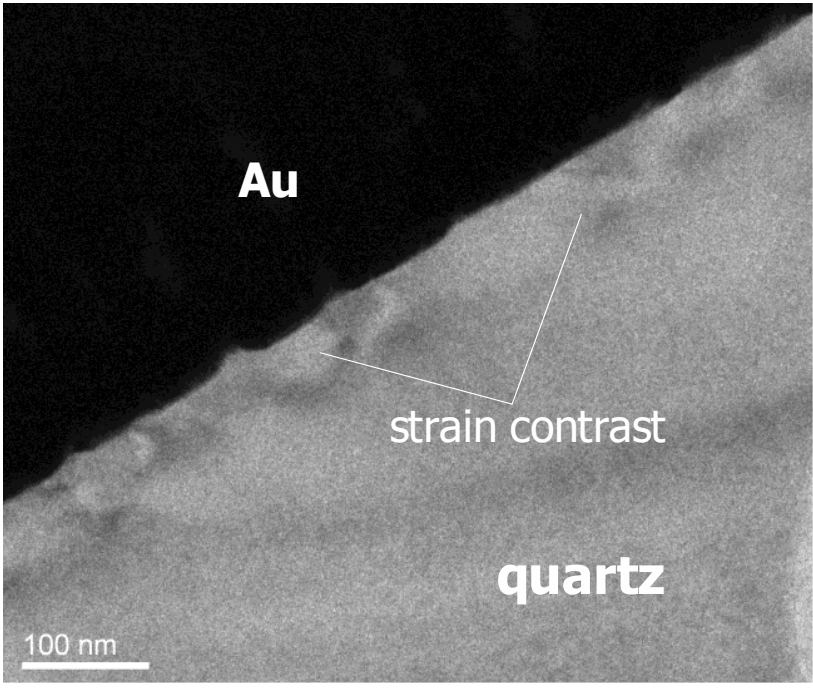
similar materials behavior of the quartz. See text for further discussion.

In summary, the near-surface regions of the three minerals imaged reveal no features that could plausibly contribute to anomalous diffusion behavior. With the exception of a narrow region of minor strain contrast ( $\sim 25 \mathrm{~nm}$ wide in the case of $\mathrm{SCO}, \sim 50 \mathrm{~nm}$ in the feldspar and quartz) the near-surface is indistinguishable from the deep interior of the minerals. The strain contrast and implied minor lattice strain are believed to be caused by atomic forces between the thin edge of the TEM foil and the Au coat, and/or by implantation of Ga ions used in FIB milling. The strain contrast is most apparent in the nearsurface of the cleaved Itrongay feldspar, and in that case it may be attributed mainly to the cleaving process itself (Figure 5). Even if the strain-contrast zone imaged in the thin TEM foils is also present in the 3-D specimens used for diffusion studies, most diffusion profiles penetrate substantially deeper than this zone. It must be borne in mind, also, that the imaged specimens were not thermally annealed as is the case with any specimen used in a high-temperature diffusion experiment. 


\section{Discussion}

\section{1 \\ 5.1. Integrity of the near-surface of polished samples}

The results of this study confirm beyond any reasonable doubt that the near-surface region of a

properly polished mineral specimen is representative of the bulk crystal structure in terms of its

194 diffusion properties. The exception to this generalization is the outermost 1-2 $\mathrm{nm}$ region (the

195 immediate near-surface), within which the atoms can be relaxed from their normal lattice positions, and

196 where the impurity content and diffusion properties may differ for those of the bulk crystal. As

197 demonstrated graphically by Pinilla et al. (2012), cutting and polishing of silicates can introduce

198 numerous dislocations in the outer micrometer or so of a crystal; however, the creation of this damage

199 during the initial cutting and grinding of the crystal and its removal during the final polishing steps

200 depends critically on the procedures used. Undesired near-surface lattice damage is easily avoided with 201 proper precautions during sample preparation.

$202 \quad$ 5.2. Consistency of diffusion results from different types of studies

The preceding conclusion should not be surprising. In addition to the documentation provided by

204 Cherniak et al. (2014) in the form of direct imaging by AFM and FE-SEM, there exists a long and growing 205 history of substantial agreement between diffusion data acquired by depth-profiling of the near-surface 206 region and results from other experimental, analytical and computational techniques. Diffusants and 207 host minerals for which such agreement has been achieved include: Fe-Mg exchange in olivine; $\mathrm{Sr}, \mathrm{Pb}$ 208 and REE in apatite; $\mathrm{Pb}$ and REE in zircon; $\mathrm{Ca}$ in olivine; He in olivine; He in zircon; He in apatite, and many 209 other diffusants and host crystals (see Table 1). In addition to the consistency among diffusion results 210 from various techniques, the RPI group and other workers have made substantial efforts to show by 211 indirect means that the measured diffusion behavior of at least some species (including noble gases) is 212 in fact insensitive to surface preparation procedure. For example, Ryerson et al. (1989) measured 213 indistinguishable oxygen diffusivities in olivine for samples prepared by polishing, polishing and etching, 
215 indistinguishable results for Ar diffusion into quartz whether the surface is a natural growth facet or one

216 prepared by cutting and polishing as described in section 3.1. These authors showed, further, that pre-

217 annealing of quartz specimens at $1000^{\circ} \mathrm{C}$ for 1 week (to repair possible preparation-induced structural

218 damage) made no difference to the outcome of the subsequent diffusion experiments, suggesting that

219 the putative damage was not present in the first place. Thomas et al. (2008) conducted a similar

220 comparison of samples that were pre-annealed or not in their study of Ar diffusion in olivine, pyroxene,

221 quartz and corundum, as did Dohmen et al. (2007) in their study of Fe-Mg interdiffusion in olivine. No

222 differences attributable to the presence or absence of a pre-annealing step were noted in any of these

223 studies, which is an indirect confirmation that the near-surface of carefully prepared samples contains

224 no structural damage that affects diffusion.

Table 1. Summary of diffusion studies in which substantial agreement was achieved using different experimental, analytical and/or computational methods, either within a single study or among multiple studies. Results are considered to be in agreement based on conformance to a single Arrhenius line within reported uncertainties.

\begin{tabular}{clll} 
diffusant & mineral & \multicolumn{1}{c}{ methods* } & references \\
$\mathrm{Sr}$ & apatite & EPMA; RBS (ss, imp) & $1,2,3,4$ \\
$\mathrm{~Pb}$ & apatite & EPMA; RBS (imp) & 1,5 \\
$\mathrm{REE}$ & apatite & EPMA; RBS & 1,6 \\
$\mathrm{~Pb}$ & zircon & RBS; EPMA & 7 \\
$\mathrm{REE}$ & zircon & RBS; EPMA & 8 \\
$\mathrm{Hf}$ & zircon & RBS; EPMA & 9,10 \\
$\mathrm{Ca}$ & olivine & EPMA; SIMS; RBS & 11 \\
$\mathrm{He}$ & olivine & impl + NRA; bulk/ms; FP & $12,13,14$ \\
$\mathrm{He}$ & apatite & impl + NRA; DFT & 15,16 \\
$\mathrm{He}$ & zircon & impl + NRA; bulk/ms & 15,17 \\
$\mathrm{He}$ & periclase & impl + NRA; bulk/ms; DFT & 18 \\
$\mathrm{Sr}$ & plagioclase & RBS; SIMS & $19,20,21$ \\
$\mathrm{~Pb}$ & monazite & RBS; SIMS & 22 \\
$\mathrm{Fe}-\mathrm{Mg}$ & olivine & EPMA; ATEM & 23
\end{tabular}

* EPMA = electron microprobe; RBS = Rutherford backscattering; SIMS = ion microprobe; ss = surface source; impl = ion implantation; bulk/ms = outgassing and conventional mass spectrometry; DFT = density functional theory; FP = first principles calculations.

1. Watson et al. (1985)

2. Cherniak \& Ryerson (1993)

3. Farver \& Giletti (1989)

4. Farver \& Giletti (2001)

5. Cherniak et al. (1991)

6. Cherniak (2000a)

7. Cherniak \& Watson (2001)

8. Cherniak et al. (1997a)
9. Cherniak et al. (1997b)

10. Suzuki et al. (1992)

11. Gaetani et al. (2004)

12. Cherniak \& Watson (2012)

13. Shuster et al. (2004)

14. Wang et al. (2015)

15. Cherniak et al. (2009)

16. Djimbi et al. (2015)
17. Reiners et al. (2004)

18. Song et al. (2016)

19. Giletti \& Casserly (1994)

20. Cherniak \& Watson (1992)

21 Cherniak \& Watson (1994)

22. Cherniak et al. (2004)

23. Meissner et al. (1998) 
Just as agreement among different experimental methods confirms and substantiates laboratory-

226 based diffusion measurements (Table 1), so also do examples of consistency between laboratory results

227 and inferred diffusion behavior in natural systems (e.g., Pb diffusive closure in zircon, apatite and

228 monazite; Hodges, 2003). It would be misleading to suggest that there are no counter-examples in the

229 form of apparent discrepancies between laboratory and "natural" diffusion behavior; however, some

230 instances of apparent disagreement (e.g., Pb diffusion in rutile; Metzger et al., 1989; Smye and Stockli

231 2014; Cherniak, 2000b) may be explained by complexities in natural crystals — intragrain fast paths and

232 defect trapping, for example - that experimentalists generally seek to avoid in their efforts to

233 characterize the fundamental phenomenon of volume diffusion.

$234 \quad$ 5.3. Ion implantation damage

Ion implantation has been used extensively by materials scientists as a convenient means to

236 introduce incompatible diffusants or to alter the composition of a target material (see, e.g., Nastasi et

237 al., 1996). This discussion of near-surface damage would not be complete without brief mention of the

238 damage to the near-surface of a crystal that can result from implantation of the atoms whose

239 diffusivities we seek to measure. Ion implantation can be thought of as a brute-force method of

240 introducing diffusants into a sample and producing a region, localized at a specific depth, that is out of

241 equilibrium with the rest of the sample. In some respects ion implantation is similar to in-situ

242 production of incompatible atoms in crystals by alpha decay, where the recoiling heavy nucleus plows

243 through the crystal structure much like an implanted ion. In studies spanning more than 20 years and

244 targeting diffusants ranging from $\mathrm{He}$ to $\mathrm{Pb}$, we have used ion implantation as a complement to other

245 techniques or when other methods of introducing a diffusant fail. The crystals used in these studies are 246 prepared in the same manner as described above for in-diffusion experiments, with the polished surface

247 serving as the implantation target. In recent studies of light noble-gas (He and $\mathrm{Ne}$ ) diffusion in minerals, 248 we have used ion-beam energies of $100-200 \mathrm{KeV}$ and typical doses of $\sim 10^{15} / \mathrm{cm}^{2}$, which results in a 
Gaussian distribution of the implanted species centered at a depth of a few hundred nanometers. In the

250 case of low-mass implants like $\mathrm{H}, \mathrm{He}$, and Li, ion energy loss (stopping) occurs mainly through electron-

251 electron interactions, so near-surface damage to the target is mainly in the form of local ionization

252 (Nastasi et al. 1996). Energy loss of heavy ions, in contrast, occurs mainly through elastic collisions,

253 during which atoms in the target can be dislodged from their normal lattice positions, creating vacancies

254 and Frenkel defects. Ionization caused by low-mass implants does not alter the atomic structure of the

255 target and is repaired upon modest heating, but heavy-ion nuclear collisions create damage trails and

256 eventual total amorphization of the target if the dose is sufficiently high. In terms of possible effects on

257 diffusion, ionization caused by low-mass implants is probably unimportant, if for no other reason than

258 that it is not thermally stable. However, the atom displacements caused by higher-mass implants are

259 reason for concern because of the direct role of vacancies in diffusion. This does not mean that

260 diffusion studies involving implantation of relatively heavy atoms are hopelessly flawed. Measures can

261 be taken to control or mitigate the damage, such as hot implantation to continuously anneal (restore)

262 the crystal structure, post-implantation annealing to restore the structure (see, e.g., Fleuster et al.

263 1994), or simply keeping the dose as low as possible and characterizing diffusion as a function of implant

264 dose. Further, the degree of retention of and recovery from implantation-induced damage will depend

265 on the characteristics of the implanted material, just as it does the case of radiation damage in natural

266 materials (e.g., Cherniak et al., 1991; Cherniak, 1993; Ewing et al. 2003; Wang et al. 1992; Weber et al.

267 1997; Meldrum et al. 1998). Cherniak and Ryerson (1993) obtained excellent agreement of Sr diffusion

268 measurements in apatite obtained by ion implantation (profiled by RBS) with the earlier study by

269 Watson et al. (1985) in which profiles were produced by in-diffusion from a surface source and

270 quantified using the electron microprobe. In a similar vein, Cherniak et al. (2014) showed that $\mathrm{Ne}$

271 diffusivities obtained from ion implantation experiments are in excellent agreement with Ne diffusivities 
272 measured by in-diffusion from an external gas source. This agreement confirms the common-sense

273 view that, once atoms are diffusively mobile, they have no memory of where they came from.

Another vitally important aspect of ion implantation experiments is that they involve relaxation of

275 an implanted (Gaussian) concentration profile in both directions - i.e., back out through the region of

276 the crystal that was traversed by the implanted ions and deeper into the sample where the structure

277 was unaffected by implantation. Symmetrical relaxation of the initial Gaussian profile therefore means

278 that diffusion behavior in the (possibly damaged) near-surface is the same as that in the pristine deeper

279 (undamaged) crystal. Symmetrical spreading of the implanted Gaussian profile is evident in the studies

280 of Cherniak and Ryerson (1993) and Cherniak et al. (2014), among others, which confirm in yet another

281 way that the diffusion measurements from implanted samples are robust.

In addition to structural damage in the region of the crystal traversed by energetic ions, ion

283 implantation can cause damage at the immediate surface of the sample. Through AFM imaging,

284 Cherniak et al. (2014) showed that surface sputtering is a by-product of Ne implantation in forsterite.

285 The sputtering by Ne ions leads to visible surface roughness not present in the polished samples. The

286 relief is modest, however, $( \pm 10 \mathrm{~nm})$ and tends to flatten during the diffusion anneal. As noted by

287 Watson and Dohmen (2010), depth-profiling techniques such as RBS and NRA that average information

288 over relatively large areas $\left(\sim 1 \mathrm{~mm}^{2}\right)$ perpendicular to the depth-profiling direction are generally

289 insensitive to surface roughness - provided that roughness is not attributable to residual source

290 particles adhering to the surface. This is true in cases where the iso-concentration contours follow the

291 surface topography, and also when the surface relief is small relative to the length scale of the diffusion

292 profile (see Figure 12 e-g of Watson and Dohmen, 2010). 
For an in-depth discussion of ion implantation and ion-solid interactions, the reader is referred to

294 Nastasi et al. (1996); Watson and Dohmen (2010) provide a basic primer on ion implantation and

295 diffusion measurements on materials of geochemical interest.

296 5.4. Significance of near-surface concentrations obtained by depth-profiling with RBS or NRA depth-profiling of in-diffusion profiles in the near-surface region. Here we consider the specific case of diffusion experiments in which the sample was exposed to a powder source during the experiment that was subsequently removed prior to depth profiling by RBS or NRA, which average concentration vs. depth information over a large area (typically $\sim 1 \mathrm{~mm}^{2}$ ). A useful example is Ti diffusion in quartz, which was characterized by Cherniak et al. (2007) using the powder-source method for the majority of the 38 experiments reported. In that study, natural and synthetic quartz specimens were polished as described 304 in section 3.1 and pre-annealed at $1200^{\circ} \mathrm{C}$ for one day prior to use in diffusion experiments. The design of the powder-source experiments was straightforward: the quartz specimens were packed in $\sim 2-\mu \mathrm{m}$ commercial $\mathrm{TiO}_{2}$ powder and held at temperatures ranging between $650^{\circ} \mathrm{C}$ and $1200^{\circ} \mathrm{C}$ for durations up to 85 days. The quartz samples were then recovered from the furnace, cleaned ultrasonically to remove the $\mathrm{TiO}_{2}$ powder, and depth-profiled for Ti using RBS.

In principle, diffusive uptake profiles can yield quantitative information not only for diffusion but 310 also for thermodynamic quantities - e.g., solubilities and partition coefficients - because the 311 concentration of the diffusant at the surface of the diffusion specimen (beyond the INS; see section 2)

312 should reflect equilibrium with the diffusant source. The theory and methodology for obtaining 313 accurate information on both diffusion and element partitioning has been discussed in detail by previous workers (Watson and Green, 1981; Dohmen et al., 2003; Dohmen and Chakraborty, 2003; Faak

315 et al., 2013); here we emphasize a potential limitation specifically of the powder-source method 
commonly utilized at RPI in recent decades. In the experiments of Cherniak et al. (2007), for example,

317 the surface concentration of Ti in quartz obtained by depth-profiling should, ideally, be equivalent to the 318 solubility of $\mathrm{TiO}_{2}$ in quartz at the conditions of the experiments. The authors showed that this was the 319 case to a very rough approximation (their Figure 5). However, additional information on $\mathrm{TiO}_{2}$ solubility 320 in quartz has been obtained since 2007 (Thomas et al., 2010; 2015), and the now-recognized pressure 321 effect means that $\mathrm{TiO}_{2}$ solubilities are nearly an order of magnitude higher at 1 atmosphere than

322 Cherniak et al. (2007) could have known. This re-definition of equilibrium solubilities leads to the 323 conclusion that nearly all of the surface concentrations obtained by depth-profiling powder-source 324 diffusion experiments are lower than the equilibrium $\mathrm{TiO}_{2}$ solubilities, in many cases by as much as an 325 order of magnitude. Superficially, this observation could be interpreted as an indictment of the 326 diffusion experiments. However, it must be borne in mind that even a fine powder source of $\sim 2 \mu \mathrm{m}$ 327 grain size represents imperfect coverage of the surface: at best, it amounts to a high density of point 328 contacts of the powder with the polished surface of the diffusion sample (see Figure 11 of Watson and 329 Dohmen, 2010). The "mating" of the diffusant source with the surface is imperfect by design, because complete removal of the source from the mineral surface following an experiment is required for accurate depth profiling by RBS or NRA (which would be precluded by continuous bonding of the source

332 to the surface). In the absence of effective surface diffusion or vapor-phase transport, the incomplete

333 (literally "spotty") coverage of the powder source is generally expected to result in underestimated 334 surface concentrations. In summary, because the powder-source method may involve non-uniform 335 surface coverage at a scale much smaller than the analytical footprint, it is neither intended nor 336 expected to be a reliable source of equilibrium solubility and partitioning data. The values of the 337 diffusivities determined from the depth profiles are in no way compromised by this fact, because the 338 recovered diffusivity is determined mainly by the length scale of diffusant penetration into the sample, 339 and a uniform distribution over the surface is not required for extraction of an accurate diffusivity 
340 (Tannhauser, 1956). The fact that powder-source diffusion experiments may not yield useful solubility

341 or partitioning information in no way diminishes their effectiveness and value in diffusion studies.

342 Rutherford backscattering spectroscopy and NRA are particularly well suited to depth profiling of

343 powder-source diffusion experiments because they average concentration vs. depth information over a

344 large area of the sample surface.

\section{Concluding remarks}

The broad conclusion from the TEM images obtained in this study is that concentration profiles

347 produced by diffusion from a surface source into the outermost few hundred nanometers of carefully

348 polished crystals should accurately reflect volume diffusion in the bulk crystal. This finding does not

349 eliminate the need to evaluate reproducibility and lack of time-dependence in laboratory investigations

350 of diffusion in Earth and planetary materials, but we hope it will ease concerns that experimental studies

351 of diffusants whose sluggishness necessitates high-resolution depth profiling are subject to damage-

352 related influences that do not exist in nature (e.g., Spandler and O'Neill, 2010; Pinilla et al., 2012). This

353 does not mean, however, that quantitative thermodynamic significance can in all cases be attributed to

354 spatially-averaged surface concentrations from depth profiles produced by in-diffusion from surface

355 sources that are non-uniform at a microscopic scale.

In contrast to in-diffusion studies conducted on carefully polished crystals, the use of ion

357 implantation to introduce diffusants does cause structural damage to the crystal, the nature and extent

358 of which depends upon the mass and energy of the implanted ions. In terms of its effect on diffusion of

359 the implanted species, ion implantation damage has been shown to be of no consequence for elements

360 of $Z \leq 10$ if the implant dose is held to relatively low levels $\left(\sim 10^{15} / \mathrm{cm}^{2}\right)$. Implantation damage is

361 manageable for heavier ions under some circumstances, depending on the mineral identity, implanted

362 species, total implant dose and other conditions of implantation. 
Acknowledgements. This work was supported by NSF grant nos. EAR-0738843 and EAR-0948204 to EBW and an NSERC Discovery grant to JMH. We thank the following individuals for expert assistance with instrument operation and various aspects of sample preparation for electron microscopy: M. David Frey of the MNCR at RPI for assistance with FIB/FE-SEM characterization; Glenn Piercey at Memorial University of Newfoundland for help with the gold coating prior to the TEM foil preparation, and Anja Scheiber for assistance with the FIB TEM foil preparation at the German Research Centre GFZ, Potsdam. 


\section{References}

Beilby, G.T., 1921. Aggregation and Flow of Solids. Macmillan, New York.

Chakraborty, S., Rubie, D.C., $1996 . \mathrm{Mg}$ tracer diffusion in aluminosilicate garnets at $750-850^{\circ} \mathrm{C}, 1 \mathrm{~atm}$ and $1350^{\circ} \mathrm{C}, 8.5 \mathrm{GPa}$. Contrib. Mineral. Petrol. $122,406-414$.

Cherniak, D.J., 2000a, Rare earth element diffusion in apatite. Geochim. Cosmochim. Acta 64, 38713885.

Cherniak, D.J., 2000b, Pb diffusion in rutile: Contrib. Mineral. Petrol., 139, 198-207.

Cherniak, D.J., Ryerson, F.J., 1993. A study of strontium diffusion in apatite using Rutherford backscattering spectroscopy and ion implantation. Geochim. Cosmochim. Acta 57, 4653-4662.

Cherniak, D.J., Watson, E.B., 1992, A study of strontium diffusion in K-feldspar, Na-K feldspar and anorthite using ion implantation and Rutherford backscattering spectroscopy. Earth Planet. Sci. Lett. $113,411-425$.

Cherniak, D.J., Watson, E.B., 1994. A study of strontium diffusion in plagioclase using Rutherford backscattering spectroscopy. Geochim. Cosmochim. Acta 58, 5179-5190.

Cherniak, D.J., Watson, E.B., 2001, Pb diffusion in zircon. Chem. Geol. 172, 5-24.

Cherniak, D.J., Watson, E.B., 2012, Diffusion of helium in olivine at 1 atmosphere and 2.7 GPa. Geochim. Cosmochim. Acta 84, 269-279.

Cherniak, D.J., Lanford, W.A., Ryerson, F.J., 1991. Lead diffusion in apatite and zircon using ion implantation and Rutherford backscattering techniques. Geochim. Cosmochim. Acta 55, 16631673.

Cherniak, D.J., Hanchar, J.M., Watson, E.B., 1997a, Rare earth diffusion in zircon. Chem. Geol. 136, 289301.

Cherniak, D.J., Hanchar, J.M., Watson, E.B., 1997b, Diffusion of tetravalent cations in zircon. Contrib. Mineral. Petrol. 127, 383-390.

Cherniak, D.J., Watson, E.B., Grove, M., Harrison, T.M., 2004, Pb diffusion in monazite: a combined RBS/SIMS study. Geochim. Cosmochim. Acta 68, 829-840.

Cherniak, D.J., Watson, E.B., Thomas, J.B., 2009, Diffusion of helium in zircon and apatite. Chemical Geology 268, 155-166.

Cherniak, D.J., Thomas, J.B., Watson, E.B., 2014. Neon diffusion in olivine and quartz. Chemical Geology $371,68-82$.

Chrisey, D.B., Hubler, G.K. (eds), 1994. Pulsed Laser Deposition of Thin Films. Wiley, New York. 
Djimbi, D.M., Gauthero, C., Roques, J., Tassan-Got, L., Gerin, C., Simoni, E., 2015, Impact of apatite chemical composition on (U-Th)/He thermochronometry: An atomistic point of view. Geochimica et Cosmochimica Acta 167, 162-176.

Dohmen, R., Chakraborty, S., 2003. Mechanism and kinetics of element and isotopic exchange mediated by a fluid phase. Am. Mineral. 88, $1251-1270$.

Dohmen, R., Chakraborty, S., Becker, H.-W., 2002b. Si and O diffusion in olivine and implications for characterizing plastic flow in the mantle. Geophys. Res. Lett. 29, DOI:10.1029/2002GL015480.

Dohmen, R., Chakraborty, S., Palme, H., Rammensee, W., 2003. The role of element solubility on the kinetics of element partitioning: in situ observations and a thermodynamic kinetic model. J. Geophys. Res. 108, B3, Article 2157, doi:10.1029/2001JB000587.

Dohmen, R., Becker, H.-W., Meissner, E., Etzel, T., Chakraborty, S., 2002a. Production of silicate thin films using pulsed laser deposition (PLD) and applications to studies in mineral kinetics. Eur. J. Mineral. 14, 1155-1168.

Dohmen, R., Becker, H.-W., Chakraborty, S., 2007. Fe-Mg diffusion in olivine I: experimental determination between 700 and $1,200^{\circ} \mathrm{C}$ as a function of composition, crystal orientation and oxygen fugacity. Phys. Chem. Miner. 34, 389-407.

Dowben, P.A., Miller, A., 1990. Surface Segregation Phenomena. CRC Press, Boca Raton, Florida, U.S.A.

Ewing, R.C., Meldrum, A., Wang, L.M., Weber, W.J., Corrales, L.R., 2003, Radiation effects in zircon. Rev Mineral. Geochem. 53, 387-425.

Faak, K., Chakraborty, S., Coogan, L.A., 2013. Mg in plagioclase: Experimental calibration of a new geothermometer and diffusion coefficients. Geochimica et Cosmochimica Acta 123, 195-217.

Farver, J.R., Giletti, B.J., 1985. Oxygen diffusion in amphiboles. Geochim. Cosmochim. Acta 49, 14031411.

Farver, J.R., Giletti, B.J., 1989, Oxygen and strontium diffusion kinetics in apatite and potential applications to thermal history determinations. Geochim. Cosmochim. Acta 53, 1621-1631.

Farver, J.R., Giletti, B.J.,,, 2001, Calcium and strontium diffusion in apatite. 11th annual V. M. Goldschmidt conference. LPI Contribution, abstract no. 3734.

Fenter, P., Geissbuhler, P., DiMasi, E., Srajer, G., Sorensen, L. B., Sturchio, N. C., 2000a. Surface speciation of calcite observed in situ by high-resolution $\mathrm{X}$-ray reflectivity. Geochim. Cosmochim. Acta $64,1221-1228$.

Fenter, P., Teng, H., Geissbuhler, P., Hanchar, J.M., Nagy, K.L., Sturchio, N.C., 2000b. Atomic-scale structure of the orthoclase (001)-water interface measured with high-resolution X-ray reflectivity. Geochim. Cosmochim. Acta 64, 3663-3673.

Fenter, P., McBride, M.T., Srajer, G., Sturchio, N.C., Bosbach, D., 2001. Structure of barite (001)- and (210)-water interfaces. J. Phys. Chem. B 105, 8112-8119. 
Fenter, P., Cheng, L., Park, C., Zhang, Z. and Sturchio, N.C., 2003. Structure of the orthoclase (001)- and (010)-water interfaces by high-resolution X-ray reflectivity. Geochim. Cosmochim. Acta 67, 42674275.

Finch, G.I., Quarrell, A.G., Roebuck, J.S., 1934. The Beilby Layer. Proc. R. Soc. Lond. A 145, 676-681.

Fleuster, M., Buchal, C., Snoeks, E., Polman, A., 1994. Optical and structural properties of MeV erbiumimplanted $\mathrm{LiNbO}_{3}$. J. Appl. Phys. 75, 173-180.

Fortier, S.M., Giletti, B.J., 1991. Volume self-diffusion of oxygen in biotite, muscovite, and phlogopite micas. Geochim. Cosmochim. Acta 55, 1319-1330.

French, R.C., 1933. Polish on metals. Proc. R. Soc. Lond. A 140, 637-652.

Gaetani, G.A., Hirth, G., Cherniak, D.J., 2004, Diffusion of Ca in San Carlos Olivine at 800 to $1200^{\circ} \mathrm{C}$, American Geophysical Union, Fall Meeting 2004, abstract no. V24A-07.

Giletti, B.J., 1991. Rb and Sr diffusion in alkali feldspars, with implications for cooling histories of rocks. Geochim. Cosmochim. Acta 55, 1331-1343.

Giletti, B. J., Casserly, J.E.D., 1994. Sr diffusion kinetics in plagioclase feldspars. Geochim. Cosmochim. Acta 58, 3785-3793.

Hall, R.N., 1953. Segregation of impurities during the growth of germanium and silicon crystals. J. Phys. Chem. 57, 836-842.

Hiraga, T., Kohlstedt, D.L., 2007. Equilibrium interface segregation in the diopside-forsterite system I: analytical techniques, thermodynamics, and segregation characteristics. Geochim Cosmochim Acta 71, 1266-1280.

Hodges, K. V., 2003, Geochronology and Thermochronology in Orogenic Systems, in Rudnick, R. L., ed., Treatise on Geochemistry, Volume 3: The Crust, Amsterdam, Elsevier Science, p. 263 - 292.

Jaoul, O., Houlier, B., Abel, F., 1983. Study of ${ }^{18} \mathrm{O}$ diffusion in magnesium orthosilicate by nuclear microanalysis. J. Geophys. Res. 88, 613-624.

Kingery, W.D., 1984. Segregation phenomena at surfaces and at grain boundaries in oxides and carbides. Solid State Ionics 12, 299-307.

Lanzillo, N.A., Watson, E.B., Thomas, J.B., Nayak, S.K., Curioni, A., 2014. Near-surface controls on the composition of growing crystals: Car-Parrinello molecular dynamics (CPMD) simulations of Ti energetics and diffusion in alpha quartz. Geochim. Cosmochim. Acta 131, 33-46.

Lowndes, D.H., Geohegan, D.B., Puretzky, A.A., Norton, D.P., Rouleau, C.M., 1996. Synthesis of novel thin-film materials by pulsed laser deposition. Science $273,898-903$.

Marquardt, K., Petrishcheva, E., Abart, R., Gardés, E., Wirth, R., Dohmen, R., Becker, H.-W., Heinrich, W., 2010. Volume diffusion of ytterbium in YAG: thin-film experiments and combined TEM-RBS analysis. Phys. Chem. Minerals 37, 751-760. 
Marschall, H.R., Dohmen, R., Ludwig, T., 2013. Diffusion-induced fractionation of niobium and tantalum during continental crust formation. Earth Planet. Sci. Lett. 375, 361-371.

Meissner, E., Sharp, T.G., Chakraborty, S., 1998. Quantitative measurement of short compositional profiles using analytical transmission microscopy. Am. Mineral. 83, 546-552.

Meldrum, A., Boatner, L.A., Weber, W.J., Ewing, R.C., 1998, Radiation damage in zircon and monazite. Geochim. Cosmochim. Acta 62,2509-2520.

Mezger,K., Hanson,G., Bohlen,S.,1989, High-precision UPb ages ofmetamorphic rutile:application to the cooling history of high-grade terranes. Earth Planet.Sci.Lett. 96, 106-118.

Nastasi, M.A., Mayer, J.W., Hirvonen, J.K., 1996. Ion-solid Interactions: Fundamentals and Applications. Cambridge University Press.

Pinilla, C., Davis, S.A., Scott, T.B., Allan, N.L., Blundy, J.D., 2012. Interfacial storage of noble gases and other trace elements in magmatic systems. Earth Planet. Sci. Lett. 319-320, 287-294.

Ratteron, P., Béjina, F., Doukhan, J.C., Jaoul, O., Libermann, R.C., 1998. Olivine/Fe-metal equilibrium under high pressure: an ATEM investigation. Phys. Chem. Minerals 25, 485-493.

Reddy, K.P.R., Cooper, A.R., 1982. Oxygen diffusion in sapphire. J. Am. Ceram. Soc. 65, 634-638.

Reiners, P.W., Spell, T.L., Nicolescu, S., Zanetti, K.A., 2004, Zircon (U-Th)/He thermochronometry: He diffusion and comparisons with ${ }^{40} \mathrm{Ar} /{ }^{39} \mathrm{Ar}$ dating. Geochim. Cosmochim. Acta 68, 1857-1887.

Ryerson, F.J., Durham, W.B., Cherniak, D.J., Lanford, W.A., 1989. Oxygen diffusion in olivine: effect of oxygen fugacity and implications for creep. J. Geophys. Res. 94, 4105-4118.

Ryerson, F.J., McKeegan, K.D., 1994. Determination of oxygen self-diffusion in akermanite, anorthite, diopside, and spinel: Implications for oxygen isotopic anomalies and the thermal histories of Ca-Al rich inclusions. Geochim. Cosmochim. Acta 58, 3713-4734.

Sano, J., Ganguly, J., Hervig, R., Dohmen, R., Zhang, X., 2011. Neodymium diffusion in orthopyroxene: Experimental studies and applications to geological and planetary problems. Geochim. Cosmochim. Acta 75, 4684-4698.

Schlegel, M. L., Nagy, K. L., Fenter, P., Sturchio, N. C., 2002. Structures of quartz (10ī0) and (10і̄1) water interfaces determined by X-ray reflectivity and atomic force microscopy of natural growth surfaces. Geochim. Cosmochim. Acta 66, 3037-3054.

Sharp, Z.D., Giletti, B.J., Yoder, H.S., 1991. Oxygen diffusion rates in quartz exchanged with $\mathrm{CO}_{2}$. Earth Planet. Sci. Lett. 107, 339-348.

Shuster, D. L., Farley, K. A., Sisterson, J. M., Burnett, D. S., 2004, Quantifying the diffusion kinetics and spatial distribution of radiogenic ${ }^{4} \mathrm{He}$ in minerals containing proton-induced ${ }^{3} \mathrm{He}$. Earth Planet. Sci. Lett. 217, 19-32. 
Smye, A.J., Stockli, D. F., 2014, Rutile U-Pb age depth profiling: A continuous record of lithospheric thermal evolution Earth Planet. Sci. Lett. 408, 171-182.

Sneeringer, M., Hart, S.R., Shimizu, N., 1984. Strontium and samarium diffusion in diopside. Geochim. Cosmochim. Acta 48, 1589-1608.

Spandler, C., O'Neill, H. St. C., 2010. Diffusion and partition coefficients of minor and trace elements in San Carlos olivine at $1300^{\circ} \mathrm{C}$ with some geochemical implications. Contrib. Mineral. Petrol. 159, 791-818.

Sutton, A.P., Balluffi, R.W., 1995. Interfaces in Crystalline Materials. Clarendon Press, Oxford.

Suzuki, K., Kouta, H., Nagasawa, H., 1992, Hf-Zr interdiffusion in single crystal zircon. Geochem. J. 26, 99104.

Thomas, J.B., Cherniak, D.J., Watson, E.B., 2008. Lattice diffusion and solubility of argon in forsterite, enstatite, quartz and corundum. Chem. Geol. 253, 1-22.

Thomas, J.B, Watson, E.B., Spear, F.S., Shemella, P.T., Nayak, S.K., Lanzirotti, A. (2010) TitaniQ under pressure: the effect of pressure and temperature on Ti-in-quartz solubility. Contrib. Mineral. Petrol. 160, 743-759.

Thomas, J.B., Watson, E.B., Spear, F.S., Wark D.A. (2015) TitaniQ recrystallized: experimental confirmation of the original Ti-in-quartz calibrations. Contrib. Mineral. Petrol. 169:27. DOI: 10.1007/s00410-015-1120-0.

Tirone, M., Ganguly, J., Dohmen, R., Langenhorst, F., Hervig, R., Becker, H.-W., 2005. Rare earth diffusion kinetics in garnet: Experimental studies and applications. Geochim. Cosmochim. Acta 69, 23852398.

Van Orman, J.A., Grove, T.L., Shimizu, N., 1998. Uranium and thorium diffusion in diopside. Earth Planet. Sci. Lett. 160, 505-519.

Van Orman, J.A., Grove, T.L., Shimizu, N., 2001. Rare earth element diffusion in diopside: influence of temperature, pressure, and ionic radius, and an elastic model for diffusion in silicates. Contrib. Mineral. Petrol. 141, 687-703.

Van Orman, J.A., Grove, T.L., Shimizu, N., Layne, G.D., 2002. Rare earth element diffusion in a natural pyrope single crystal at $2.8 \mathrm{GPa}$. Contrib. Mineral. Petrol. 142, 416-424.

Wang, K., Brodholt, J., Lu, X., 2015, Helium diffusion in olivine based on first principles calculations. Geochim. Cosmochim. Acta 156, 145-153.

Wang, L.M., Cameron, M., Weber, W.J., Crowley, K.D., Ewing, R.C., 1994, In situ TEM observation of radiation induced amorphization of crystals with the apatite structure. In Hydroxyapatite and Related Materials. Brown, P.W., Constantz, B. (eds.), CRC Press, p. 243-249.

Wark, D.A., Watson, E.B. (2006) TitaniQ: a titanium-in-quartz geothermometer. Contrib. Mineral. Petrol. $152,743-754$. 
Wartho, J., Kelley, S.P., Brooker, R.A., Carroll, M.R., Villa, I.M., Lee, M.R., 1999. Direct measurement of Ar diffusion profiles in gem-quality Madagascar potassium feldspar using the ultra-violet laser ablation microprobe (UVLAMP). Earth Planet. Sci. Lett. 170, 143-151.

Watkins, J.M., DePaolo, D.J., Watson, E.B., 2016. Kinetic fractionation of non-traditional stable isotopes by reaction and diffusion. Reviews in Mineralogy and Geochemistry _, Mineralogical Society of America (submitted).

Watson, E.B., Cherniak, D.J., 2003. Lattice diffusion of Ar in quartz, with constraints on Ar solubility and evidence of nanopores. Geochim. Cosmochim. Acta 67, 2043-2062.

Watson, E.B., Dohmen, R., 2010. Non-traditional and emerging methods for diffusion measurements. In: Diffusion in Minerals and Melts (Y. Zhang and D. Cherniak, Eds.) Reviews in Mineralogy and Geochemistry 72, Mineralogical Society of America.

Watson, E.B., Green, T.H., 1981. Apatite/liquid partition coefficients for the rare earth elements and strontium. Earth Planet. Sci. Lett. 56, 405-421.

Watson, E.B., Harrison, T.M., Ryerson, F.J., 1985. Diffusion of Sm, $\mathrm{Sr}$ and $\mathrm{Pb}$ in fluorapatite. Geochim. Cosmochim. Acta 49, 1813-1823.

Weber, W.J., Ewing, R.C., Meldrum, A., 1997, The kinetics of alpha-decay-induced amorphization in zircon and apatite containing weapons grade plutonium and other actinides. J. Nucl. Mater. 250, 147-155.

Winkelmann, A., 2010. Principles of depth-resolved Kikuchi pattern simulation for electron backscatter diffraction. J. Microsc. 239, 32-45. doi:10.1111/j.1365-2818.2009.03353.x.

Wirth, R., 2004. A novel technology for advanced application of micro- and nanoanalysis in geosciences and applied mineralogy. Eur J Mineral 16, 863-876.

Zaefferer, S., 2007. On the formation mechanisms, spatial resolution and intensity of backscatter Kikuchi patterns. Ultramicroscopy 107, 254-266. doi:10.1016/j.ultramic.2006.08.007.

Zhang, Y., Cherniak, D.J. (eds), 2010. Diffusion in Minerals and Melts, Rev. Mineral. Geochem. 72, Mineralogical Society of America, Chantilly, Virginia, U.S.A.

Zhang, Z., Fenter, P., Sturchio, N.C., Bedzyk, M.J., Machesky, M.L., Wesolowski, D.J., 2007. Structure of rutile $\mathrm{TiO}_{2}(110)$ in water and 1 molal $\mathrm{Rb}^{+}$at $\mathrm{pH}$ 12: inter-relationship among surface charge, interfacial hydration structure, and substrate structural displacements. Surf. Sci. 601, 1129-1143. 